\title{
Hybrid zones between invasive Rorippa austriaca and native $R$. sylvestris (Brassicaceae) in Germany: ploidy levels and patterns of fitness in the field
}

\author{
W Bleeker and A Matthies \\ Department of Systematic Botany, University of Osnabrück, Barbarastr. 11, 49076 Osnabrück, Germany
}

\begin{abstract}
Hybrid zones may serve as natural laboratories for evolutionary studies. One common viewpoint is that hybrids may always be less fit than their parents due to genetic discontinuities. An alternative idea is that genotype-environment interactions influence the outcome of natural hybridization. Our comparative study of two different natural hybrid zones between the invasive diploid Rorippa austriaca and the native polyploid $R$. sylvestris in Germany identified the ploidy level as a major determinant of hybrid fitness. Different ploidy levels and patterns of fitness were detected in different
\end{abstract}

hybrid zones. In one hybrid zone (Mülheim, Ruhr valley) hybrids were pentaploid and showed a relatively high seed set, whereas in the second hybrid zone (Randersacker, Main valley) hybrids were triploid and displayed extremely low fitness values. Analyses of fitness values in different natural hybrid zones between the same two species may lead to very different conclusions about the evolutionary significance of natural hybridization.

Heredity (2005) 94, 664-670. doi:10.1038/sj.hdy.6800687

Published online 20 April 2005

Keywords: AFLP; chloroplast DNA; flow cytometry; hybrid fitness; invasive species

\section{Introduction}

A central question in the study of hybrid zone evolution has been whether hybrids are always less fit than their parents due to genetic discontinuities or whether hybrid fitness varies (Arnold and Hodges, 1995). Most interspecific hybrids recognized in the field have been recorded as highly or completely sterile based on seed set (Stace, 1975). In contrast, many recent studies indicate that hybrids may show high variation in fitness (Arnold and Hodges, 1995; Arnold et al, 2001; Bleeker, 2004) and provide evidence for genotype-environment interactions (Campbell and Waser, 2001, Johnston et al, 2003).

To test the evolutionary importance of hybridization in a given species complex, it is critical that findings from greenhouse experiments be tested in the field (Arnold et al, 2001). Only very few measurements of hybrid fitness have been conducted under natural conditions (Rieseberg and Carney, 1998). Multiple hybrid zones between the same two species offer excellent opportunities for a comparative approach.

Rorippa austriaca is a diploid $(2 \mathrm{n}=16)$ perennial species native to western Asia and southeastern Europe (Jonsell, 1973). For several decades it has been invasive in Germany. R. sylvestris is a native perennial species which is common all over Germany and central Europe. Different ploidy levels, tetraploids $(2 \mathrm{n}=32)$, hexaploids $(2 n=48)$, and rarely pentaploids $(2 n=40)$, have been

Correspondence: W Bleeker, Department of Systematic Botany, University of Osnabrück, Barbarastr. 11, 49076 Osnabrück, Germany.

E-mail: bleeker@biologie.uni-osnabrueck.de

Received 4 October 2004; accepted 10 March 2005; published online 20 April 2005 detected in R. sylvestris (Jonsell, 1968). Multiple introductions of $R$. austriaca into central Europe are leading to repeated possibilities for the formation of contact zones with native species. Independent local hybridization and bidirectional introgression between $R$. austriaca and the native $R$. sylvestris (L.) Besser $(2 n=32,48)$ have been detected in a recent study using molecular markers (Bleeker, 2003).

The goal of the present study was to test common predictions on hybrid fitness (hybrids are uniformly less fit, hybrid fitness varies) in different natural hybrid zones and to draw conclusions about the repeatability of hybridization processes along the invasive/native species border line. Therefore, we examined differences in pollen production, pollen viability, seed production, and seed germination in two hybrid zones located in Mülheim (Ruhr valley) and Randersacker (Main valley). Flow cytometry and molecular markers were used to investigate the ploidy level and the genetic constitution of hybrid genotypes. The trn $\mathrm{L}$ intron (chloroplast DNA) of $R$. austriaca shows a species specific deletion of $169 \mathrm{bp}$ (Bleeker et al, 2002; Bleeker, 2003). This deletion was used to analyse the maternal parentage of hybrids. AFLP analysis was performed to prove hybrid origins based on the distribution of species-specific parental markers (Marhold et al, 2002; Bleeker, 2003; Lamont et al, 2003).

\section{Materials and methods}

\section{Plant material}

The hybrid zones that were analysed are located at riversides in Mülheim in the Ruhr valley between Essen 
and Duisburg (N 51 $27^{\prime}$ E $06^{\circ} 50^{\prime}$ ) and Randersacker (N $49^{\circ} 45^{\prime}$ E $\left.09^{\circ} 58^{\prime}\right)$ at the river Main south of Würzburg. A map is given in Bleeker (2003). In spring 2002 individual plants were marked using waterproof plastic strips (Dymo label manager $100+$; Esselte NV, Belgium). Owing to our experiences in 2000 and 2001, we were either able to identify $R$. austriaca, $R$. sylvestris, and their hybrids in the field or knew their exact locations from the results of molecular analyses. In the Mülheim hybrid zone, we marked 13 individuals of $R$. austriaca, 28 individuals of $R$. sylvestris, and five hybrids. In the Randersacker hybrid zone, eight individuals of $R$. austriaca, nine individuals of $R$. sylvestris, and eight hybrids were marked. Both hybrid zones are rather small explaining the unequal and low sample numbers. Additional populations of $R$. austriaca and $R$. sylvestris grew in the vicinity of both collection sides (appr. $100 \mathrm{~m}$ ), but no additional hybrids were detected in a circle of $500 \mathrm{~m}$ around the sampled plants. Fresh leaf material of all marked individuals was collected in silica gel for molecular analyses. Both sites were revisited during the reproductive period to harvest pollen, seeds, and leaf material for flow cytometry analyses from the same individual plants.

\section{Ploidy analysis}

Flow cytometry was used for the determination of relative DNA amount. Fresh leaf material was harvested in the field and stored at $4{ }^{\circ} \mathrm{C}$ for 1-2 days until further analyses. Approximately $0.5 \mathrm{~cm}^{2}$ leaf material was chopped with a sharp razor blade in a DAPI solution and filtered into a sample tube. Subsequent flow cytometry analysis was performed on a Partec Ploidy Analyser-I (Partec, Münster, Germany). The diploid $R$. islandica (Oeder) Borbas $(2 \mathrm{n}=16)$ was used as an internal standard.

\section{Chloroplast DNA analysis}

Total DNA was isolated from silica-gel-dried leaf material using the CTAB method of Doyle and Doyle (1987). The trnL intron was amplified using the ' $c$ ' and ' $d$ ' primers of Taberlet et al (1991). Amplifications were performed following the protocol of Franzke et al (1998). Amplification products were resolved on $1.5 \%$ agarose gels and visualized by UV light after staining with ethidium bromide. The length of the amplification products was estimated using a standard $100 \mathrm{bp}$ ladder.

\section{AFLP analysis}

AFLP analysis followed the protocol of Vos et al (1995) with minor modifications. DNA was isolated from silicagel-dried material collected in the field (see above), digested with restriction enzymes EcoRI and MseI for $2 \mathrm{~h}$ at $37^{\circ} \mathrm{C}$ and simultaneously ligated to double-stranded EcoRI and MseI adapters. Preselective amplifications were performed using primers with a one base pair extension. In a second selective amplification, the number of fragments was further reduced by primers with a three base pair extension. For the second amplification, we used the primer combinations MseICTA/EcoRI-AAC and MseI-CTA/EcoRI-AAG, which revealed high resolution in a previous study (Bleeker, 2003). Selective amplification products were separated electrophoretically on an ABI 377 (Perkin Elmer) with an internal standard (GeneScan 500 Rox, ABI).

\section{Fitness components}

The mean number of pollen grains per flower was estimated by counting the pollen grains from five flower buds per individual plant. The flowers of Rorippa show, like most of the Brassicaceae, six anthers that are arranged in two rings (four anthers in the inner ring, two anthers in the outer ring). The pollen grains of two anthers of the inner ring and one anther of the outer ring from each bud were dissected on a microscope slide and counted using a counting grid. The number of pollen grains per bud was estimated using the following equation: Pollen grains per bud $=2$ (number of grains in first inner anther + number of grains in second inner anther) +2 (number of grains in outer anther).

Pollen viability was tested by lactophenol blue staining of pollen grains. Five freshly opened anthers of different flowers per individual plant were incubated in lactophenol blue solution for 2-3 days (Brochmann, 1992). The fraction of stained pollen grains was estimated under a microscope. The total number of seeds produced by each individual was investigated by destructive sampling. All ripe fruits were harvested before opening and the seeds were removed and counted.

Germination experiments were performed in a controlled environment cabinet with a regime of $14 \mathrm{~h}$ daylight $20^{\circ} \mathrm{C} / 10 \mathrm{~h}$ night $5^{\circ} \mathrm{C}$. Seeds were germinated on sterile soil (FLORAGARD TKS 1/sand 3:1) using pots of $11 \mathrm{~cm}$ diameter. Light was supplied by PHILIPS lamps type MGR102-400. A maximum of 100 seeds were sown per pot. Pots were checked for newly emerging seedlings every 3 days. After 10 weeks, no new seedlings were observed and the experiment was stopped. The percentage of germinated seeds was calculated.

\section{Data analysis}

In the AFLP analysis, hybrids were identified by additive banding patterns of diagnostic parental markers. Markers were viewed as diagnostic when occurring in all analysed individuals of one parent species but not in the other parent species (Bleeker, 2003). The mean number of pollen grains per flower, pollen viability, seed number, and seed germination were analysed using a two-way analysis of variance (ANOVA) with fixed factors of class (R. austriaca, R. sylvestris, hybrids) and site (Mülheim, Randersacker). The mean number of pollen grains per flower was analysed on a log scale. The computations were performed using SPSS 11.0 (SPSS Inc.).

\section{Results}

\section{Ploidy analysis}

Five different groups could be distinguished based on the relative DNA amount of 69 individuals (Figure 1). The DNA amount of the 21 analysed individuals of $R$. austriaca did not differ from the internal standard (diploid $R$. islandica =1s). R. austriaca was thus diploid in both invasive populations. $R$. sylvestris in Randersacker was tetraploid, and the relative DNA amount varied between $1.94 \mathrm{~s}$ and $2.07 \mathrm{~s}(\mathrm{n}=7)$. Two individuals of $R$. sylvestris from Randersacker were not analysed. $R$. sylvestris in Mülheim was hexaploid showing consider- 


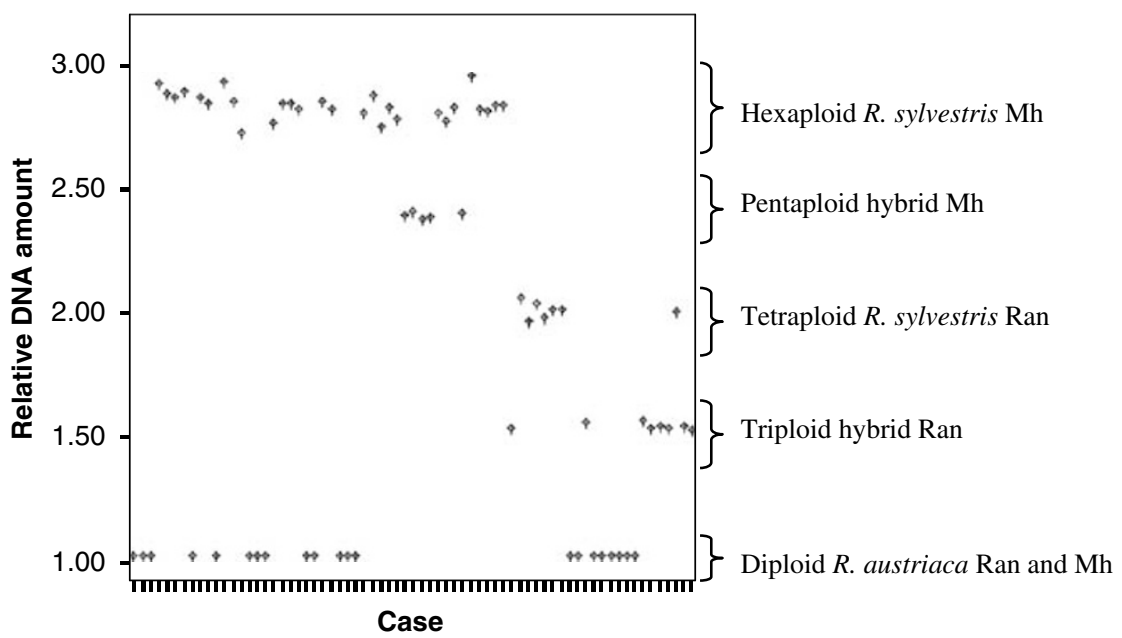

Figure 1 Relative DNA amount of 69 individuals collected in two natural hybrid zones between R. austriaca and R. sylvestris in Germany. The diploid $R$. islandica was used as an internal standard (=1s).

able variation in relative DNA amount (2.7s-2.92s; $\mathrm{n}=28$ ). Tetraploid and hexaploid individuals of $R$. sylvestris with known chromosome numbers $(2 \mathrm{n}=32$, $2 n=48$ ) were used as additional reference material and gave peaks within the range of $R$. sylvestris plants collected in Randersacker and Mülheim, respectively, supporting our data interpretation. The hybrids in Randersacker and Mülheim showed different ploidy levels (Figure 1). In Randersacker, the hybrids were all triploid (1.5s-1.54s; $\mathrm{n}=8$ ). The Mülheim hybrids showed much higher values than would be expected from a hybrid between a diploid and a hexaploid (2s). They were most likely pentaploid showing relative DNA amounts between $2.35 \mathrm{~s}$ and $2.38 \mathrm{~s}(\mathrm{n}=5)$.

\section{TrnL intron analysis}

The $t r n \mathrm{~L}$ intron of 71 individuals of $R$. austriaca, $R$. sylvestris, and the hybrid was amplified. Two different trn $\mathrm{L}$ intron amplification product length variants (approximately 420 and $590 \mathrm{bp}$, respectively) were detected by visual interpretation of the agarose gels (Table 1). $R$. austriaca was characterized by a $t r n \mathrm{~L}$ intron amplification product length variant of $420 \mathrm{bp} ; R$. sylvestris always showed the $590 \mathrm{bp}$ length variant. All five hybrid individuals in Mülheim showed the R. austriaca specific length variant $(420 \mathrm{bp})$. Both length variants were detected in the Randersacker hybrids - three individuals showed the $420 \mathrm{bp}$ length variant and five individuals were characterized by the $590 \mathrm{bp}$ length variant.

\section{AFLP analysis}

A total of 71 individuals of R. austriaca (21 individuals), R. sylvestris (37 individuals), and their putative hybrid (13 individuals) were investigated. AFLP analysis yielded a total of 167 bands (AFLP loci). Of these 154 were polymorphic $(92.2 \%)$ and 13 monomorphic $(7.8 \%)$. In all, 15 different AFLP phenotypes (nine in Mülheim and six in Randersacker) were detected in R. austriaca; R. sylvestris showed 31 different AFLP phenotypes (22 in Mülheim and nine in Randersacker, Table 2). In both hybrid zones, the hybrids showed additive banding patterns of parental-specific AFLP markers. The distri-
Table 1 Distribution of two trnL intron amplification product length variants in two hybrid zones between $R$. austriaca and $R$. sylvestris

\begin{tabular}{lrcc}
\hline & $\mathrm{n}$ & $420 \mathrm{bp}$ & $590 \mathrm{bp}$ \\
\hline $\begin{array}{l}\text { Hybrid zone Mülheim } \\
\text { R. austriaca }\end{array}$ & 13 & 13 & \\
$\begin{array}{l}\text { R. sylvestris } \\
\text { Hybrids }\end{array}$ & 28 & - & - \\
$\quad 5$ & 5 & - \\
Hybrid zone Randersacker & & & \\
R. austriaca & 8 & 8 & - \\
R. sylvestris & 9 & - & 9 \\
Hybrids & 8 & 3 & 5 \\
\hline
\end{tabular}

Table 2 Number of AFLP phenotypes and mean number of AFLP markers detected in two hybrid zones between $R$. austriaca and R. sylvestris

\begin{tabular}{lrcr}
\hline & $\mathrm{n}$ & n phenotypes & $\begin{array}{c}\text { Mean number of } \\
\text { markers }( \pm s d)\end{array}$ \\
\hline $\begin{array}{l}\text { Hybrid zone Mülheim } \\
\text { R. austriaca }\end{array}$ & 13 & 9 & $66.92 \pm 8.77$ \\
$\begin{array}{l}\text { R. sylvestris } \\
\text { Hybrids }\end{array}$ & 28 & 22 & $66.96 \pm 6.29$ \\
Hybrid zone Randersacker & 5 & 3 & $72.4 \pm 3.04$ \\
$\quad$ R. austriaca & 8 & 6 & \\
R. sylvestris & 9 & 9 & $73.5 \pm 3.71$ \\
Hybrids & 8 & 5 & $90.25 \pm 3.99$ \\
\hline
\end{tabular}

bution of the different diagnostic markers in Mülheim and Randersacker is shown in Figure 2. In the Mülheim hybrid zone the hybrids were characterized by three diagnostic $R$. austriaca markers and seven diagnostic $R$. sylvestris markers. In all, 10 diagnostic $R$. austriaca markers and 10 diagnostic $R$. sylvestris markers were detected in the Randersacker hybrids. In order to estimate the genomic constitution of the triploid and pentaploid hybrids, we analysed the total number of markers detected in the analysed taxa and the percentage 


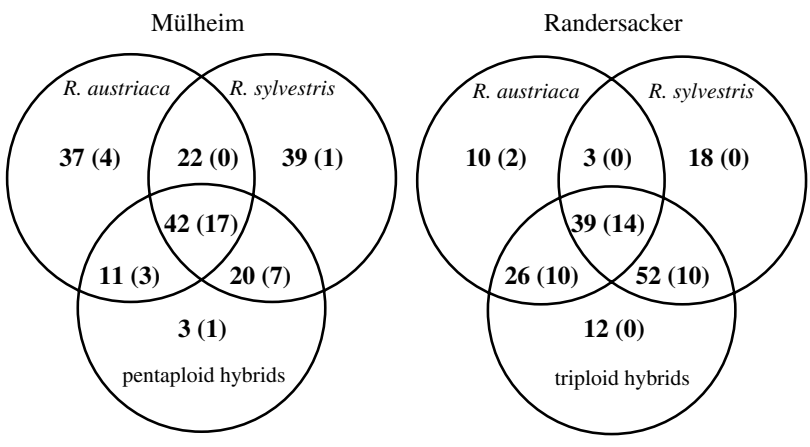

Figure 2 Distribution of the different AFLP markers detected in two natural hybrid zones between $R$. austriaca and $R$. sylvestris in Germany. The number of markers detected in all individuals of the respective classes or intersections is given in parentheses.

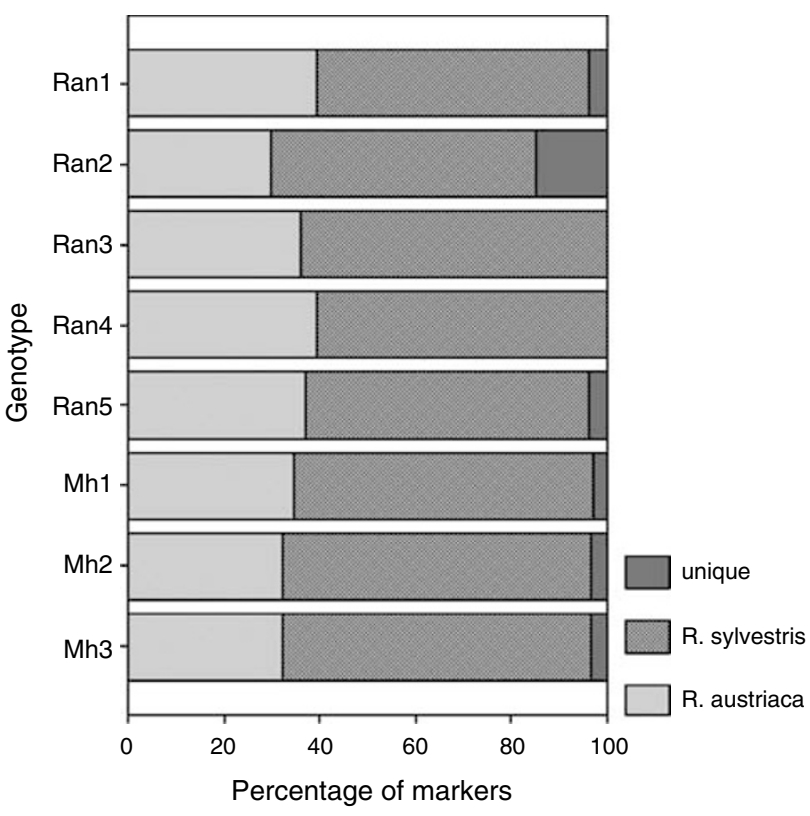

Figure 3 Percentage of $R$. austriaca markers, R. sylvestris markers, and unique markers in eight hybrid genotypes detected in two natural hybrid zones between $R$. austriaca and $R$. sylvestris in Germany.

of $R$. austriaca and $R$. sylvestris markers within the observed hybrid genotypes. The total number of markers varied between taxa and between hybrid zones (Table 2). The hybrids showed the highest number of markers in both hybrid zones. The triploid Randersacker hybrids displayed more bands than the pentaploid Mülheim hybrids. Tetraploid $R$. sylvestris from Randersacker showed more markers than hexaploid $R$. sylvestris from Mülheim. R. austriaca showed similar numbers of markers in both hybrid zones. Five different genotypes (AFLP phenotypes) were detected in eight triploid hybrid individuals in Randersacker, and three different genotypes were detected in five pentaploid hybrid individuals in Mülheim (Table 2). Figure 3 shows the percentage of $R$. austriaca markers, $R$. sylvestris markers, and unique markers within these eight hybrid geno- types. All hybrid genotypes showed higher percentages of $R$. sylvestris specific markers (55-64.5\%) compared with $R$. austriaca specific markers (32.1-39.6\%). With the exception of genotype Ran2, the triploid Randersacker hybrid genotypes (Ran1, Ran3-Ran5) showed a higher percentage of $R$. austriaca specific markers (36.2-39.6\%) than the pentaploid Mülheim hybrid genotypes (Mh1Mh3; 32.1-34.4\%). Ran2 showed the highest number of unique markers (15\%, Figure 3).

\section{Fitness components}

Unfortunately, not all marked individuals could be analysed. Some plants were lost due to the dramatic summer floods of 2002, others were grazed by cows or ducks and did not flower or no seeds could be harvested. Boxplots of the mean number of pollen per flower (a), the pollen viability as indicated by lactophenol blue staining (b), the number of seeds produced (c), and the germination rate of the seeds (d) including the number of individuals available for analyses are depicted in Figure 4. Pollen quantity, pollen viability, and germination rates differed significantly between classes $(R$. austriaca, R. sylvestris, hybrids) and sites (Mülheim, Randersacker; Table 3). Pollen quantity and pollen quality were lower in the Randersacker hybrid zone, possibly due to drought stress (Figure 4a, b). Significant between site differences in germination rates were due to the low germination rate of $R$. austriaca seeds from Mülheim (Figure 4d). The Randersacker hybrids showed the lowest pollen quantity (Figure 4a), low pollen viability (Figure $4 \mathrm{~b}$ ), and no seed set (Figure 4c). The Mülheim hybrids were also characterized by low pollen viability (Figure $4 \mathrm{~b}$ ), but showed surprisingly high seed set and germination rates of seeds (Figure 4c, d). Differences in performance, for example, between triploid and pentaploid hybrids and between tetraploid and hexaploid $R$. sylvestris, led to the detection of significant class $\times$ site interactions in all four fitness components (Table 3 ). Pollen viability and seed set of hexaploid R. sylvestris in Mülheim were much higher compared with tetraploid $R$. sylvestris in Randersacker (Figure $4 \mathrm{~b}, \mathrm{c}$ ). Seed set and germination rate of $R$. austriaca in Mülheim were lower compared with $R$. austriaca in Randersacker (Figure 4c, d).

\section{Discussion}

Our comparative study revealed different ploidy levels and patterns of fitness in different hybrid zones. Triploid hybrids detected in a hybrid zone in Randersacker had no seed set whereas pentaploid hybrids detected in a hybrid zone in Mülheim had high seed set.

\section{Genomic constitution of hybrids}

The outcome of hybridization between the invasive $R$. austriaca and the native $R$. sylvestris in central Europe may largely be determined by the ploidy level of the hybridizing native species ( $R$. sylvestris)

The formation of the triploid Randersacker hybrids can easily be explained by the fusion of reduced gametes of both parental species. The fusion of a haploid $R$. austriaca (A) gamete with a diploid $R$. sylvestris (RR) gamete would lead to a triploid F1 hybrid (RRA). The results of the chloroplast DNA analysis showed that both parental species may serve as the maternal parent, since 

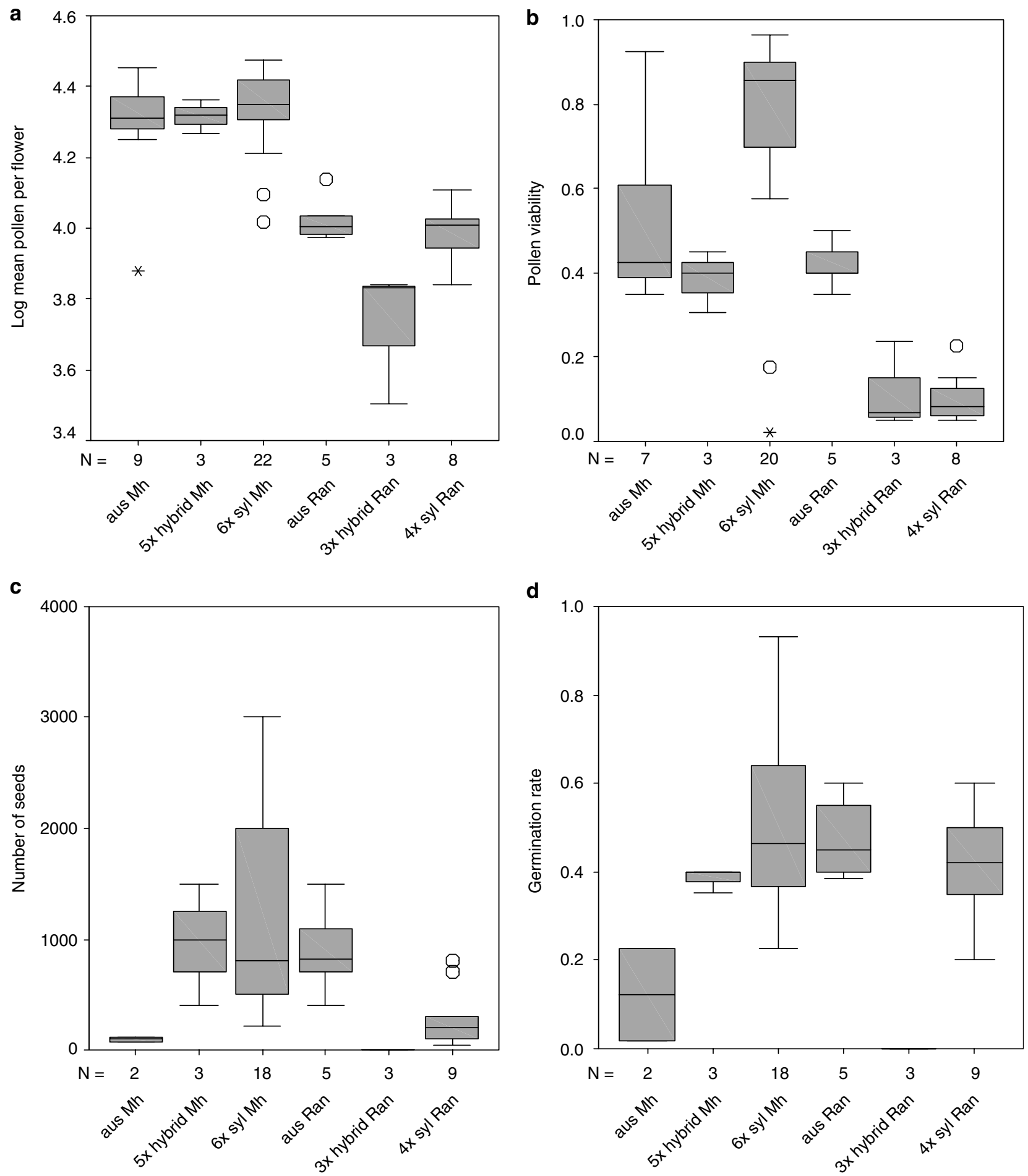

Figure 4 Boxplots of the mean number of pollen per flower (a), the pollen viability (b), the number of seeds produced (c), and germination rates (d) of $R$. austriaca, $R$. sylvestris, and their hybrid in two natural hybrid zones in Germany. Rectangles define 25 and 75 percentiles; horizontal lines show median; whiskers are from 10 to 90 percentiles.

chloroplast DNA is usually maternally inherited in the Brassicaceae (Harris and Ingram, 1991). The AFLP data are in accordance with the RRA hybrid genome, with triploid hybrids showing higher percentage of $R$. sylvestris markers than R. austriaca markers (Figure 3).
The formation of the pentaploid Mülheim hybrids is more difficult to explain, since octoploid $R$. sylvestris has never been observed in this well-studied species. At least one parental species must have contributed unreduced gametes. Unreduced gamete formation is a major 
Table 3 Two way ANOVA on mean number of pollen per flower, pollen viability, seed production, and seed germination with fixed factors class and site

\begin{tabular}{lccrc}
\hline Source of variation & $d f$ & Type III MS & F & P \\
\hline Log mean pollen per flower & & & & \\
$\quad$ Class & 2 & 0.13 & 3.69 & 0.031 \\
$\quad$ Site & 1 & 1.52 & 86.56 & 0.000 \\
Class $\times$ site & 2 & 0.19 & 5.52 & 0.006 \\
& & & & \\
Pollen viability & & & & \\
$\quad$ Class & 2 & 0.35 & 4.70 & 0.013 \\
Site & 1 & 1.16 & 31.10 & 0.000 \\
Class $\times$ site & 2 & 0.69 & 9.33 & 0.000 \\
$\quad$ & & & & \\
Seed production & 2 & 700560.10 & 0.89 & 0.415 \\
$\quad$ Class & 1 & 322572.61 & 0.83 & 0.368 \\
$\quad$ Site & 2 & 5265567.50 & 6.75 & 0.003 \\
Class $\times$ site & & & & \\
$\quad$ & 2 & 0.231 & 4.49 & 0.018 \\
Germination rate & 1 & 0.136 & 5.27 & 0.027 \\
$\quad$ Class & 2 & 0.388 & 15.1 & 0.000 \\
$\quad$ Site & & & & \\
$\quad$ Class $\times$ site &
\end{tabular}

mechanism in the evolution of polyploid plants (Bretagnolle and Thompson, 1995; Ramsey and Schemske, 1998). The high percentage of $R$. sylvestris markers in the pentaploid hybrids (Figure 3) suggests an RRRAA or RRRRA genome. $R$. austriaca was the maternal parent of all Mülheim hybrids since they contain the $420 \mathrm{bp}$ variant of the $\operatorname{trn} \mathrm{L}$ intron. A first generation RRRAA hybrid genome could be explained by unreduced gamete (egg) formation in R. austriaca. However, the low total number of AFLP markers detected in the pentaploid Mülheim hybrids compared with the triploid Randersacker hybrids (Table 2) does not support such a scenario. First generation hybrids will show high numbers of markers due to additivity while in future generations there will be recombination and a potential loss of markers. It is possible that the pentaploid hybrids evolved via a first generation RRRA hybrid ( $R$. austriaca served as the maternal parent) and subsequent backcrossing with $R$. sylvestris. The fusion of a reduced $R$. sylvestris RRR pollen with a reduced RA egg of the F1 hybrid would lead to an RRRRA pentaploid hybrid showing the $R$. austriaca chloroplast. Hybrids between R. austriaca and R. sylvestris are common in the middle Elbe region in eastern central Germany extending their range into northern Germany. Most of the existing hybrid populations are tetraploid (Jonsell, 1968; Bleeker, unpublished data); thus the formation of tetraploid hybrids between $R$. austriaca and $R$. sylvestris is possible.

\section{Hybrid fitness}

Hybrids between R. austriaca and R. sylvestris were not generally less fit than their parents. The ploidy level has been identified as a major determinant of hybrid fitness.

Many recent studies indicate that hybrids are not always characterized by low fitness and that hybrid fitness may be environment dependent (Burke et al, 1998; Johnston et al, 2001, 2003; Campbell and Waser, 2001; Emms and Arnold, 1997; Hauser et al, 2003). We were not able to test whether hybrid fitness is affected by the genomic constitution alone or also by environmental factors since we analysed different genotypes in different natural environments. However, because of their different ploidy levels, it is likely that the genomic constitution affects the fitness differences between the Mülheim and the Randersacker hybrids.

The low fertility of the triploid Randersacker hybrids is in accordance with expected problems in performing normal meiosis. Based on the extremely low fitness of the triploid (F1) hybrids, these genotypes could be interpreted as an evolutionary dead end. However, even though F1 progeny may be produced rarely and be of limited fertility, further hybrid generations may frequently be produced if there are repeated opportunities for hybridization (Arnold and Hodges, 1995). Very few or even single hybrids can be of high evolutionary importance. A well-studied example for such processes is from Senecio in the British Isles. The triploid hybrid between the native tetraploid $S$. vulgaris $L$. and the invasive diploid S. squalidus L. is highly sterile, but has acted as a bridge for introgression and also in the formation of the allohexaploid $S$. cambrensis Rosser (Abbott et al, 1992, Abbott, 1992, Abbott and Lowe, 1996).

Our finding of high seed set in pentaploid hybrids is surprising. High seed set in a pentaploid hybrid would be consistent with agamospermy. However, apomixis is not known in Rorippa or closely related genera (Cardamine L., Nasturtium R. Br., Barbarea WT Aiton). Flow cytometry data indicate that the high seed production in the pentaploid Mülheim hybrids is most likely due to backcrossing with hexaploid $R$. sylvestris (Bleeker, unpublished data). Several examples of fertile hybrids with irregular chromosome numbers are known from the Brassicaceae. The triploid hybrid Cardamine xinsueta is capable of producing fertile gametes via polarized segregation of chromosomes during meiosis (Urbanska et al, 1997). Aneuploid individuals of the watercress hybrid (Nasturtium xsterile) sometimes show a high seed set and considerable pollen viability (Bleeker et al, 1999).

As hybrid fitness parental performance is expected to vary between genotypes and between environments. Hybrids may show higher relative fitness where parents suffer from suboptimal conditions, for example, at the edge of the natural distribution areas or in invasive populations. $R$. austriaca is an invasive self-incompatible species and showed an extremely low seed set in the Mülheim population. Natural populations of self-incompatible Rorippa species often show a low seed set. This is likely due to a low number of self- incompatibility alleles within populations (Mulligan and Munro, 1984; Bleeker, 2004). In Randersacker, the geographical distance to other $R$. austriaca populations was much lower than in Mülheim, presumably resulting in a higher number of cross-compatible partners and a higher seed set.

Our study shows that it is difficult to generalize or to predict the outcome of natural hybridization even between the same two species and highlights the importance of measuring multiple fitness components. Results from different natural hybrid zones or of different fitness components may lead to very different conclusions concerning the evolutionary significance of hybridization. The formation of hybrid zones between $R$. austriaca and $R$. sylvestris in Germany is a recent phenomenon and it will be interesting to see what it might lead to in the future. 


\section{Acknowledgements}

We thank RJ Abbott, PH van Tienderen, H Hurka, and one anonymous reviewer for comments on earlier versions of the manuscript. The ploidy analysis was performed at the University of Amsterdam, Institute for Biodiversity and Ecosystem Dynamics. The presented study is part of the project 'Evolutionary consequences of biological invasions' which is financed by the German Federal Ministry of Education and Research (BIOLOG 01LC0012).

\section{References}

Abbott RJ (1992). Plant invasions, interspecific hybridization and the evolution of new plant taxa. Trend Ecol Evol 7: 401-405.

Abbott RJ, Lowe AJ (1996). A review of hybridization and evolution in British Senecio. In: Hind DJN, Beentje HJ (eds) Compositae: Systematics. Proceedings of the International Compositae Conference, Kew, 1994. Royal Botanic Gardens, Kew, pp 679-689.

Abbott RJ, Ashton PA, Forbes DG (1992). Introgressive origin of the radiate groundsel Senecio vulgaris L. var. hibernicus Syme: Aat-3 evidence. Heredity 68: 425-435.

Arnold ML, Hodges SA (1995). Are natural hybrids fit or unfit relative to their parents? Trend Ecol Evol 10: 67-71.

Arnold ML, Kentner EK, Johnston JA, Cornman S, Bouck AC (2001). Natural hybridisation and fitness. Taxon 50: 93-104.

Bleeker W (2004). Genetic variation and self-incompatibility within and outside a Rorippa hybrid zone (Brassicaceae). Plant Syst Evol 246: 35-44.

Bleeker W (2003). Hybridization and Rorippa austriaca (Brassicaceae) invasion in Germany. Mol Ecol 12: 1831-1841.

Bleeker W, Weber-Sparenberg C, Hurka H (2002). Chloroplast DNA variation and biogeography in the genus Rorippa Scop. Brassicaceae). Plant Biol 4: 104-111.

Bleeker W, Huthman M, Hurka H (1999). Evolution of hybrid taxa in Nasturtium R. Br. (Brassicaceae). Folia Geobot Phytotaxon 34: 421-433.

Bretagnolle F, Thompson JD (1995). Gametes with the somatic chromosome number: mechanisms of their formation and role in the evolution of autopolyploid plants. New Phytol 129: 1-22.

Brochmann C (1992). Pollen and seed morphology of Nordic Draba (Brassicaceae): phylogenetic and ecological implications. Nord J Bot 12: 657-673.

Burke JM, Carney SE, Arnold ML (1998). Hybrid fitness in the Lousiana Irises: Analysis of parental and F1 performance. Evolution 52: 37-43.

Campbell DR, Waser NM (2001). Genotype-by-environment interaction and the fitness of plant species in the wild. Evolution 55: 669-676.

Doyle JJ, Doyle JL (1987). A rapid DNA isolation procedure for small quantities of fresh leaf tissue. Phytochem Bull Bot Soc Amer 19: 11-15.
Emms SK, Arnold ML (1997). The effect of habitat on parental and hybrid fitness: transplant experiments with Loisiana irises. Evolution 51: 1112-1119.

Franzke A, Pollmann K, Bleeker W, Kohrt R, Hurka H (1998). Molecular systematics of Cardamine and allied genera (Brassicaceae). ITS and noncoding chloroplast DNA. Folia Geobot Phytotaxon 33: 225-240.

Harris SA, Ingram R (1991). Chloroplast DNA and biosystematics: the effect of intraspecific diversity and plastid transmission. Taxon 40: 393-412.

Hauser TP, Damgaard C, Jorgensen RB (2003). Frequencydependent fitness of hybrids between oilseed rape (Brassica napus) and weedy B-rapa (Brassicaceae). Amer J Bot 90: 571-578.

Johnston JA, Arnold ML, Donovan LA (2003). High hybrid fitness at seed and seedling life history stages in Louisiana irises. J Ecol 91: 438-446.

Johnston JA, Grise DJ, Donovan LA, Arnold ML (2001). Environment-dependent performance and fitness of Iris brevicaulis, I. fulva (Iridaceae), and hybrids. Am J Bot 88: 933-938.

Jonsell B (1968). Studies in the north-west European species of Rorippa s. str. Symb Bot Upsal 19: 1-221.

Jonsell B (1973). Taxonomy and distribution of Rorippa (Cruciferae) in the southern USSR. Svensk Bot Tidsk 67: 281-302.

Lamont BB, He T, Enright NJ, Krauss SL, Miller BP (2003). Anthropogenic disturbance promotes hybridization between Banksia species by altering their biology. J Evol Biol 16: 551-557.

Marhold K, Lihova J, Perny M, Grupe R, Neuffer B (2002). Natural hybridization in Cardamine (Brassicaceae) in the Pyrenees: evidence from morphological and molecular markers. Bot J Linn Soc 139: 275-294.

Mulligan GA, Munro DB (1984). Chromosome number and sexual compatibility in North America of Rorippa sylvestris (Cruciferae). Can J Bot 62: 575-580.

Ramsey J, Schemske DW (1998). Pathways, mechanisms, and rates of polyploid formation in flowering plants. Annu Rev Ecol Syst 29: 467-501.

Rieseberg LH, Carney SE (1998). Plant hybridization. New Phytol 140: 599-624.

Stace CA (1975). Hybridization and the Flora of the British Isles. Academic Press: London.

Taberlet P, Gielly L, Pautou G, Bouvet J (1991). Universal primers for amplification of three noncoding regions of chloroplast DNA. Plant Mol Biol 17: 1105-1109.

Urbanska KM, Hurka H, Landolt E, Neuffer B, Mummenhoff K (1997). Hybridization and evolution in Cardamine (Brassicaceae) at Urnerboden, Central Switzerland: biosystematic and molecular evidence. Plant Syst Evol 204: 233-256.

Vos P, Hogers R, Bleeker M, Reijaans M, van de Lee T, Hornes M et al (1995). AFLP: a new technique for DNA fingerprinting. Nucleic Acids Res 23: 4407-4414. 